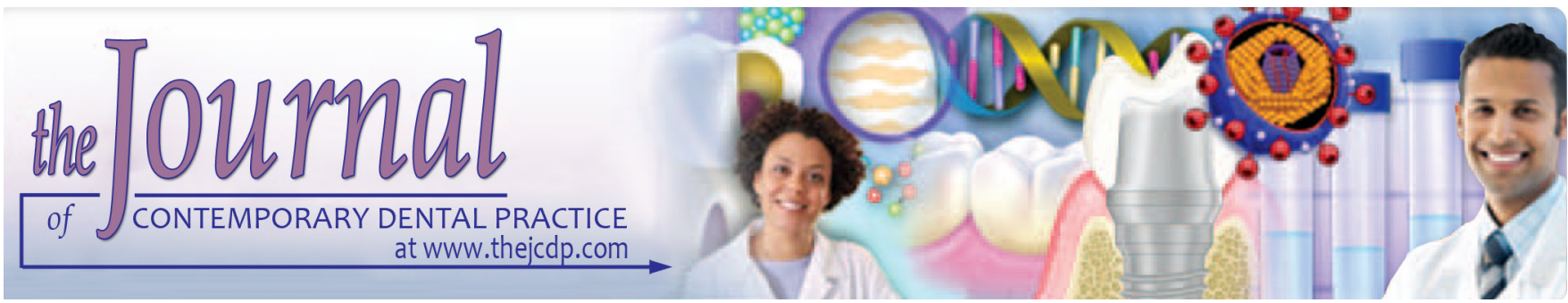

\title{
Analyses of the Erosive Potential of Various Soft Drinks and Packaged Fruit Juiceson Teeth
}

\author{
${ }^{1}$ Palak Shroff, ${ }^{2}$ Shailesh M Gondivkar, ${ }^{3}$ Subhash P Kumbhare, ${ }^{4}$ Sachin Sarode, ${ }^{5}$ Amol R Gadbail, ${ }^{6}$ Shankargouda Patil
}

\section{ABSTRACT}

Aim: This study aimed to evaluate the erosive potential of twenty beverages ( 8 carbonated drinks and 12 packaged fruit juices).

Material and methods: Twenty-one sound permanent freshly extracted teeth were segmented into small enamel slices and stored in normal saline. The titratable acidity of each experimental drink was measured as the amount of $0.1 \mathrm{~N}$ sodium hydroxide $(\mathrm{NaOH})$ required to raise $\mathrm{pH}$ to 5.5 and 7 . The enamel specimens were incubated in freshly collected human saliva for 3 hours. One enamel slice was immersed in each beverage and percentage weight loss in the enamel slice was calculated after 6 and 24 hours intervals.

Results: The titratable acidity values of the experimental drinks ranged from 0.2 to 5.6. The mean titratable acidity values of the packaged fruit juices were higher than carbonated drinks. A significant difference $(p<0.05)$ was found in the percentage weight loss of enamel specimens after 6 and 24 hours immersion in the carbonated drinks than packaged fruit juices. Apple juice followed by thumps up were found to be the most erosive drinks with the least effects of Miranda and Guava juice.

${ }^{1}$ Government Dental College and Hospital, Nagpur Maharashtra, India

${ }^{2,3}$ Department of Oral Medicine and Radiology, Government Dental College and Hospital, Nagpur Maharashtra, India

${ }^{4}$ Department of Oral Pathology and Microbiology, Dr D.Y. Patil Dental College and Hospital, Dr D.Y. Patil Vidyapeeth, Pune, Maharashtra, India.

${ }^{5}$ Department of Dentistry, Indira Gandhi Government Medical College and Hospital, Nagpur, Maharashtra, India.

${ }^{6}$ Department of Maxillofacial Surgery and Diagnostic Sciences, Division of Oral Pathology, College of Dentistry, Jazan University, Jazan, Kingfom of Saudi Arabia

Corresponding Author: Shailesh M. Gondivkar, Department of Oral Medicine and Radiology, Government Dental College and Hospital, Nagpur, Maharashtra, India. Phone: +919604121273, e-mail: shailesh_gondivkar@yahoo.com
Conclusion: Most of the beverages tested in this study showed erosive potential. The carbonated drinks caused significant dental erosion.

Clinical significance: Individuals at risk for beverages-associated erosion, particularly those with high intakes or decreased salivary flow, should be provided preventive guidance regarding habits of beverages intake. Specific dietary recommendations for the prevention of dental erosion may now be developed based on the patient's history of beverage consumption.

Keywords: Carbonated drinks, critical $\mathrm{pH}$, dental erosion, fruit juices, titratable acidity

How to cite this article: Shroff P, Gondivkar SM, Kumbhare SP, Sarode S, Gadbail AR, Patil S. Analyses of the Erosive Potential of Various Soft Drinks and Packaged Fruit Juiceson Teeth. J Contemp Dent Pract 2018;19(12):1547-1552.

Source of support: Nil

Conflict of interest: None

\section{INTRODUCTION}

The term erosive tooth wear refers to chemicalmechanical processes in which abrasive forces remove the softened layer attacked by nonbacterial acids, causing several extrinsic and intrinsic factors cause loss of hard substance of tooth. ${ }^{1}$ Dental erosion. Along with intrinsic acid (gastrointestinal), extrinsic factors include various dietary substances, medicaments, ${ }^{2,3}$ and certain environmental factors. ${ }^{4}$ Dental erosion can involve both deciduous and permanent dentition. 5,6

Currently, increased consumption of soft drinks and fruit juices has been popularised as a part of healthy dietary components, ${ }^{7}$ substituting water and posing risk for dental hard tissues erosion. ${ }^{8}$ Along with global increase in consumption of soft drinks and fruit juices, ${ }^{9,10}$ reports suggest increasing sale of soft drinks and fruit juices in India and expects to grow in future. The increasing number of production companies has made these beverages easily available in the market. Moreover, changes in the lifestyle of the Indian population in 
last two decades continuously increasing demands of these beverages. This has resulted in a major concern considering both erosive and cariogenic potential of these soft drinks and fruit juices. ${ }^{11-13}$

It is known that consumption of soft drinks results in an apparent fall in salivary $\mathrm{pH}$. This occurs depending on the intrinsic $\mathrm{pH}$ value and buffering capacity of the drinks. A pH of 5.5 is considered to be the 'critical $\mathrm{pH}^{\prime}$ for enamel dissolution. ${ }^{14}$ However, other important factors including type/amount of acid containing, titratable acidity, buffering capacity, the temperature of the drink determines the enamel dissolution abilities of these drinks. Moreover, an organic acid produced by fermentation of sugar contents of the drinks by the microorganisms present in the plaque further lead to demineralization and caries. ${ }^{15}$ A positive association has been reported between the excessive consumption of these drinks and dental erosion. ${ }^{12,13}$ Because of increasing consumption of soft drinks and fruit juices in the Indian population, the present study was conducted to analyse the erosive potential of different commercially available soft drinks and packaged fruit juices in the central part of India.

\section{MATERIALS AND METHODS}

\section{Setting and Samples}

The present study was conducted in the Department of Oral Medicine and Radiology, Government Dental College and Hospital, Nagpur and Department of Microbiology, Government Medical College and Hospital, Nagpur. Twenty-one sounds permanent teeth that were freshly extracted for orthodontic treatment purpose were collected from the Department of Oral and Maxillofacial S urgery, Government Dental College and Hospital and private practitioners in Nagpur city of India. Before extraction, patients were informed about the use of their teeth for research purpose, and their oral consent was obtained.

\section{Ethical Considerations}

Ethics approval was applied for and obtained from the Institutional Ethics Committee of Government Dental College and Hospital, Nagpur.

\section{Preparation of Samples}

The collected teeth were thoroughly cleaned and sterilized in a $5 \%$ sodium hypochlorite solution. The teeth were segmented by using a carborundum disk in a low-speed straight handpiece into small slices which approximately measured $1 \mathrm{~mm} \times 3 \mathrm{~mm} \times 3 \mathrm{~mm}$ (thickness $\times$ length $\times$ width). All the enamel specimens were then stored in saline at room temperature till further experiment.

\section{Experimental Drinks}

Twenty popular brands of soft drinks and fruit juices available in the Indian market including eight carbonated beverages and 12 packaged fruit juices were tested in this study. Bottled drinking water was used as the control. The titratable acidity of the experimental drinks was measured as the amount of $0.1 \mathrm{~N}$ Sodium hydroxide $(\mathrm{NaOH})$ required to raise the $\mathrm{pH}$ to 5.5 and 7. To degas, the carbonated drinks were stirred for 10 minutes at room temperature before use in the experiment.

\section{Study Design}

Initially, a fresh stimulated human saliva was collected in an ice-cooled tube from a healthy adult donor at least 1 hour after the donor had consumed any food or drink. ${ }^{16}$ Verbal consent was obtained from the saliva donor. The enamel specimens were cleaned with tap water and incubated in freshly collected human saliva ( $20 \mathrm{~mL} / 6$ enamel specimens) for 3 hours at room temperature. Immediately prior to the experimental procedure, the enamel specimen were rinsed with tap water, with deionized water and air-dried carefully. The weight of each enamel specimen was measured by using a microbalance (Fig. 1). One enamel slice was then immersed in each test drink.

Additionally, one enamel slice was immersed in bottled drinking water and was considered as control. The weight of all 32 enamel slice s was then measured at 6 (first erosive challenge) and 24 hours (second erosive challenge) interval. Weight loss at each interval was measured as percentage weight loss in relation to preimmersion weight.

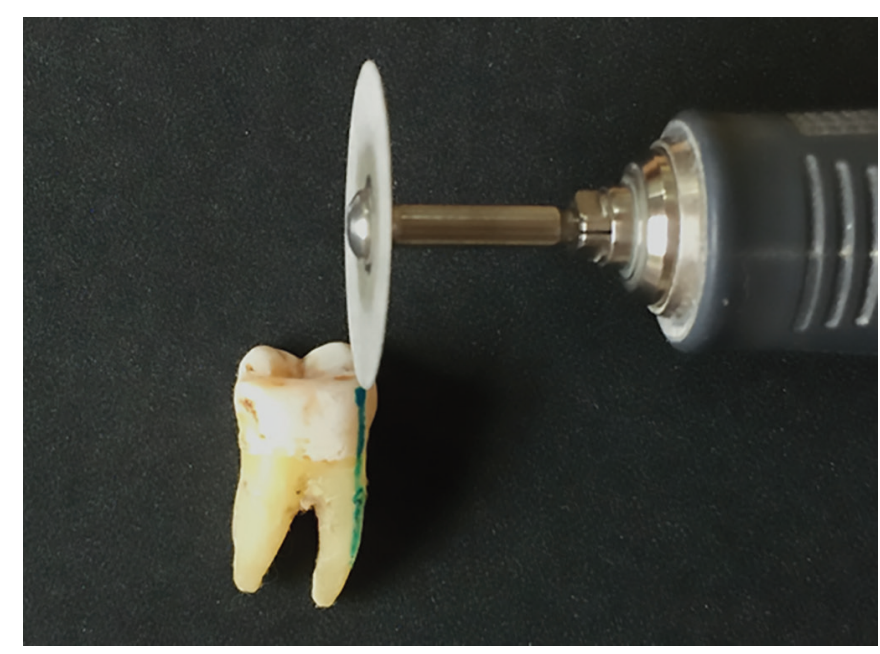

Fig. 1: Photograph showing $1 \mathrm{~mm}$ sample preparation using carborundum disk 


\section{Statistical Analysis}

The collected data were tabulated in the excel sheet and analyzed using Statistical Package for Social Sciences (SPSS) 17.0. Mann-Whitney U test was used to analyze the significance of difference for titratable acidity, percentage weight loss between the categories of drinks. A p-value of less than 0.05 was considered significant.

\section{RESULTS}

Table 1 represents the details of the twenty experimental drinks used in the study. Of all the experimental drinks, Mirinda required a minimal amount of $\mathrm{NaOH}(0.2 \mathrm{~mL})$ to raise the $\mathrm{pH}$ to 7 . However, the maximum amount of $\mathrm{NaOH}$ was required to raise the $\mathrm{pH}$ up to $5.5(5.6 \mathrm{~mL})$ and $7(9.3 \mathrm{~mL})$ respectively for apple juice. The mean titratable acidity to reach $\mathrm{pH}$ of 5.5 and 7 respectively was noticed to be higher for the packaged fruit juices than carbonated beverages $(p>0.05)$ (Table 2). The titratable acidity of the drinking bottled water was very minimum.
The percentage weight loss (in milligrams) of enamel specimens ranged from 1.05(Miranda) to 11.76 (apple juice) with a mean of 2.16 after immersion for 6 hours into experimental drinks. Whereas, 24 hours post-immersion percentage weight loss ranged from 1.05 (Miranda) to 14.70 (apple juice) with a mean of 4.74. Thumsup among the carbonated drinks and apple juice among the packaged fruit juices were found to be the most erosive drinks after both first and second erosive challenges. Regarding chemical parameters, both these beverages had the highest titratable acidity among the carbonated drinks and packaged fruit juices respectively. Interestingly, the erosive abilities of most of the beverages have significantly increased between the firs $t$ and second erosive challenges.

In contrast, though Miranda and Guava juice caused a minimal mineral loss after 6 hours immersion, no further enamel dissolution was reported between first and second erosive challenges. Moreover, a significant difference $(p<0.05)$ was found in the percentage weight loss of enamel specimens after 6 and 24 hours immersion

Table 1: Basic information of the experimental drinks used in the study

\begin{tabular}{|c|c|c|c|c|}
\hline Experimental drink & $\begin{array}{l}\text { Brand name/ } \\
\text { producer }\end{array}$ & Flavor & Erosion-related constituents & $\begin{array}{l}\text { Titratable } \\
\text { acidity } 5.5\end{array}$ \\
\hline \multicolumn{5}{|l|}{ Carbonated drinks } \\
\hline Thums up & Coca-cola company & Cola & $\begin{array}{l}\text { Phosphoric acid, carbonic acid, caffeine, acidity } \\
\text { regulators }\end{array}$ & 3.8 \\
\hline Coca-cola & Coca-cola company & Cola & Phosphoric acid, carbonic acid & 3.2 \\
\hline Fanta & Coca-cola company & Orange & Orange fruit, citric acid, carbonic acid & 3.1 \\
\hline Sprite & Coca-cola company & Lemon & Phosphoric acid, citric acid, acidity regulators & 2.9 \\
\hline Mirinda & Pepsico & Orange & Carbonic acid, acidity regulators & 0.2 \\
\hline 7-up & Pepsico & Lemon & Carbonic acid, citric acid, acidity regulators & 2.2 \\
\hline Pepsi & Pepsico & Cola & Phosphoric acid, citric acid, carbonic acid & 2.7 \\
\hline Limca & Coca-cola company & Lemon & Carbonic acid, acidity regulators & 2.7 \\
\hline \multicolumn{5}{|l|}{ Packaged fruit juices } \\
\hline Fizz mango & Parle agro India & Mango & Mango juice, acidity regulators & 3.9 \\
\hline Pineapple & Pepsico & Pineapple & Pineapple juice, acidity regulators & 4.8 \\
\hline Frooty & Parle Agro & Mango & Mango juice, citric acid & 3.6 \\
\hline Raasna & Piomalnd & Orange & Orange juice, acidity regulators & 2.9 \\
\hline Mixed fruit & Pepsico & Mixed fruit & $\begin{array}{l}\text { Mixed fruit juice (banana, apricot, pineapple, } \\
\text { mango, orange, apple, lime, and strawberry), acidity } \\
\text { regulators }\end{array}$ & 3.9 \\
\hline Apple & Parle agro India & Apple & Apple juice, acidity regulators & 5.6 \\
\hline Pomegranate & Pepsico & Pomegranate & Pomegranate juice, acidity regulators & 4.2 \\
\hline Maaza & Coca-cola company & Mango & Mango juice, acidity regulators & 3.7 \\
\hline Fruits and veggies & Pepsico & Apple & $\begin{array}{l}\text { Apple juice, beetroot juice, carrot juice, acidity } \\
\text { regulators }\end{array}$ & 4.3 \\
\hline Black plum (Jamun) & Paper boat & Black plum & Black plum juice, lemon juice, acidity regulators & 0.9 \\
\hline Guava & ITC & Guava & Guava juice, acidity regulators & 0.5 \\
\hline $\begin{array}{l}\text { Sweet lime } \\
\text { (Mosambi) }\end{array}$ & Minute Maid & Sweet lime & Sweet lime, acidity regulators & 1.1 \\
\hline \multicolumn{5}{|l|}{ Bottled drinking water } \\
\hline Kinley & Coca-cola company & - & - & - \\
\hline
\end{tabular}


in the carbonated beverages as compared to the packaged fruit juices (Table 3). Thus, most of the test drinks resulted in significant enamel weight loss after both erosive challenges except for bottled drinking water.

\section{Discussion}

Although dental erosion is a multifactorial disease and depends on several intrinsic and extrinsic factors, it is highly influenced by changing habits and lifestyles. The increased consumption of carbonated drinks and fruit juices has been a part of the modern fast-track lifestyle worldwide. India is not an exception to this; fruit juices and carbonated soft drinks are commonly consumed in India especially by children and young population. Although past studies demonstrated the association of increased consumption of soft drinks to increase in tooth erosion, there is still a substantial ignorance and paucity of literature on demineralizing effects of the packaged fruit juices on tooth enamel. The current study presented the erosive impact of various packaged fruit juices and carbonated soft drinks on the enamel of a tooth. In accordance to the past research, we noticed that several soft drinks and packaged fruit juices available in India have the significant potential of dental enamel erosion.

It is well known that frequent consumption of acidic drinks causes enamel dissolution due to their $\mathrm{pH}$ lower than the critical $\mathrm{pH}^{14}$ The acidic contents of these soft drinks including citric acid, phosphoric acid, and carbonic acid can result in $\mathrm{pH}$ to be as low as 2.6 which has shown erosive potential. ${ }^{17}$ Although acute consumption of these beverages have a negligible effect on dental enamel, the prolonged contact time between tooth enamel and soft drinks increases the chances of enamel demineralization. ${ }^{18,19}$ Under normal circumstances, the salivary secretions increases in the oral cavity in response to consumption of beverages and clears off the acid from the tooth surface to restrict erosion. However, individuals

Table 2: $\mathrm{P}$-values comparing the amount of $\mathrm{NaOH}$ in $\mathrm{ml}$ to raise the $\mathrm{pH}$ to 5.5 and 7

\begin{tabular}{llll}
\hline$p H$ & Beverages & Mean $(S D)$ & $p$-value \\
\hline 5.5 & Packaged fruit juices & $3.28( \pm 1.62)$ & 0.135 \\
& Carbonated drinks & $2.6( \pm 1.07)$ & \\
7 & Packaged fruit juices & $4.69( \pm 1.15)$ & 0.231 \\
& Carbonated drinks & $3.91( \pm 1.35)$ & \\
\hline
\end{tabular}

with the limited salivary flow are at increased risk of enamel dissolution. ${ }^{20}$ Additionally, holding such acidic beverages in the oral cavity prior to swallowing obviously prolongs acid-tooth contact time and further erosion risk. ${ }^{18,21}$ As a preventive measure, though teeth brushing seems to be logical and advocated immediately following consumption of these beverages, Rios et al. observed increased tooth loss on brushing enamel immediately after exposure to acidic drinks. ${ }^{22}$

Dental enamel is made up of calcium ( $\mathrm{Ca} 2+)$, phosphate $(\mathrm{PO} 43+)$, hydroxide $(\mathrm{OH}-)$ and fluoride $(\mathrm{f}-)$ ions. ${ }^{23}$ In the oral cavity, teeth are surrounded by saliva, and enamel crystals are in continuous equilibrium with the saliva. When the teeth are exposed to substances with $\mathrm{pH}$ less than the critical $\mathrm{pH}$, the solution is unsaturated and enamel releases these mineral contents to attain a new state of equilibrium until the solution becomes saturated. ${ }^{23,24}$ This process exacerbates the demineralization of tooth enamel. Even though $\mathrm{pH}$ is considered a measure of the acidic potential, the titratable acidity of a substance may truly indicate its tooth structure erosive ability. The titratable acidity is the amount of base required to bring a solution to neutral $\mathrm{pH}$. The titratable acidity is consistent with the buffering capacity and is directly related to the concentration of undissociated form of the acid in a substance. The undissociated form of the acid has no charge and thus, diffuses more readily into the near-surface enamel layer. This species then dissociates and acts as the proton $(\mathrm{H}+)$ carrier to maintain the acidic (unsaturated) condition, consequently exacerbating further enamel dissolution. Thus, it can be considered that the substances with higher titratable acidity represents the higher erosive potential. In the present study, apple juice and Mirinda showed the highest and lowest values of titratable acidity respectively. Moreover, the packaged fruit juices had more mean titratable acidity values as compared to the carbonated soft drinks. This is in agreement with reports of the previous studies ${ }^{14,25,26}$ and suggests that the fruit juices need higher quantity of alkaline stimulated saliva to be neutralized than the carbonated soft drinks.

In the present study, apple juice followed by thumps-up showed a highest enamel weight loss after both the erosive challenges. Moreover, most of the beverages tested in this study demonstrated remarkable enamel weight

Table 3: Table showing a comparison of mineral loss (percentage weight loss) in enamel specimens caused by carbonated drinks and packaged fruit juices after 6 hours and 24 hours erosive challenges

\begin{tabular}{lllll}
\hline Erosive challenge & Beverages & $N$ & Mean $\pm S D$ & Mann-Whitney U test p-value \\
\hline \multirow{2}{*}{6 Hours } & Carbonated drinks & 8 & $4.80 \pm 3.96$ & \multirow{2}{*}{0.030} \\
& Packaged fruit juices & 12 & $3.06 \pm 3.01$ & \\
\hline \multirow{2}{*}{24 Hours } & Carbonated drinks & 8 & $12.87 \pm 6.17$ & \multirow{2}{*}{0.010} \\
& Packaged fruit juices & 12 & $6.75 \pm 3.54$ & \\
\hline
\end{tabular}


loss between the first and second erosive challenges with the exception of Miranda and guava juice. This implies that prolonged contact time of acidic beverages with the tooth surface increases the opportunity of these substances to erode the tooth enamel. Similar results were noted by Tadakmadla et al. ${ }^{14}$ and Panda et al. ${ }^{26} \mathrm{We}$ have immersed the enamel specimens into test drinks for 6 and 24 hours to simulate the effects of multiple short in vivo exposures of these beverages in individuals who consume acidic beverages for the chronic period. The use of straw during consumption of such beverages can be helpful to reduce the demineralizing effects. ${ }^{27}$

A wide variety of constituents are used in different types of the carbonated drinks and fruit juices which differs in their erosive potential. ${ }^{28,29}$ The higher calcium, phosphate and fluoride contents of the beverages restrict the extent of erosion by saturating the solution/ altering the enamel solubility. ${ }^{30,31}$ Attin et al. proposed that rinsing enamel with fluoridated acidic solutions forms a $\mathrm{CaF}_{2}$-like layer and limits the erosive effects. ${ }^{32}$ In the present study, mirinda and guava juice showed least enamel weight loss amongst all test drinks. Panda et al., in their study, reported minimal erosive effects of Miranda and 7Up. ${ }^{26}$

The present in-vitro study was performed in the laboratory. So, it was near to impossible to simulate the natural conditions of the oral cavity. However, to resemble the present study more closely to the clinical circumstances, we have kept the enamel specimens into freshly collected human saliva $(20 \mathrm{~mL} / 6$ enamel specimens). Before swallowing, $\mathrm{t}$ he maximum volume of saliva in the mouth is $1.19 \mathrm{~mL}$ and $0.96 \mathrm{~mL}$ for males and females, respectively. ${ }^{33}$ Under normal circumstances, human saliva forms a physical barrier in the form of the acquired salivary pellicle and prevents direct contact between tooth enamel surface and acidic beverages and thus, protects teeth from erosive attacks. ${ }^{34-35}$ In the present study, the enamel specimens were kept in human saliva for 3 hours before the experiment to allow the formation of salivary pellicles. However, both the erosion challenges were made without saliva. In addition, it was not possible to consider other patient-related factors such as salivary flow rate and composition, remineralization potential of saliva, drinking habits and length of the swallow.

It is important to note that the in vitro study design and fixed duration of exposure to selective test drinks pose limitations to our study. Therefore, the present study provides no utter data on enamel erosion in the oral cavity. But, reports of the present study yield a relative value of the erosive potential of the tested brands of beverages and gives a clue for ranking the most erosive soft drinks for diet counseling. Further studies are recommended with long exposure times.

\section{CONCLUSION}

Though packaged fruit juices demonstrated greater tiratable acidity values, the carbonated soft drinks caused significant dental erosion. Most of the beverages commonly consumed by children and young adolescents in India showed erosive potential. The packaged apple juice had the highest potential to erode tooth enamel. Individuals with limited saliva and habit of frequent consumption of acidic beverages are at increased risk of enamel erosion.

\section{REFERENCES}

1. Lussi A, Carvalho TS. Erosive tooth wear: a multifactorial condition of growing concern and increasing knowledge. Monogr Oral Sci 2014;25:1-15.

2. Hunter L, Patel S, Rees J. The in vitro erosive potential of a range of baby drinks. International journal of paediatric dentistry 2009;19:325-329.

3. Hunter ML, Patel R, Loyn T, Morgan MZ, Fairchild R, Rees JS. The effect of dilution on the in vitro erosive potential of a range of dilutable fruit drinks. International journal of paediatric dentistry 2008;18:251-255.

4. Wiegand A, Attin T. Occupational dental erosion from exposure to acids - a review. Occup Med 2007;57:169-176

5. Kreulen CM, Van 'tSpijker A, Rodriguez JM, Bronkhorst EM, Creugers NH, Bartlett DW. Systematic review of the prevalence of tooth wear in children and adolescents. Caries research 2010;44:151-159.

6. Carvalho TS, Lussi A, Jaeggi T, Gambon DL. Erosive tooth wear in children. Monogr Oral Sci 2014;25:262-278.

7. Bagde NI, Tumane PM. Studies on microbial flora of fruit juices and cold drinks. Asiatic J Biotechnology Resources 2011;2:454-460.

8. Harrack L, Stay J, Story M. Soft drink consumption among U.S children and adolescents. Nutritional consequences. J Am Diet Assoc 1999;99:436-441.

9. Wang X, Megert B, Hellwig E, Neuhaus KW, Lussi A. Preventing erosion with novel agents. J Dent 2011;39:163-170.

10. Nirmala SV, Subba Reddy VV. A comparative study of $\mathrm{pH}$ modulation and trace elements of various fruit juices on enamel erosion: an in vitro study. J Indian SocPedodPrev Dent 2011;29:205-215.

11. Quadri FA, Hendriyani H, Pramono A, Jafer M. Knowledge, attitudes and practices of sweet food and beverage consumption and its association with dental caries among schoolchildren in Jazan, Saudi Arabia. East Mediterr Health J 2015;21:403-411.

12. Kannan A, Ahmed MA, Duraisamy P, Manipal S, Adusumillil P. Dental hard tissue erosion rates and soft drinks-A gender based analysis in Chennai city, India. Saudi J Dent Res 2014;5:21-27.

13. Kumar S, Acharya S, Vasthare R, Singh SK, Gupta A, Debnath N. Dental caries experience in high risk soft drinks factory workers of South India: A comparative study. Ind J Dent Res 2014;25:174-177.

14. Tadakamandla J, Kumar S, Ageeli A, Vani NV, Mahesh Babu T. Enamel solubility potential of commercially available soft drinks and fruit juices in Saudi Arabia. Saudi J Dent Res 2015;6:106-109. 
15. Goel I, Navit S, Mayall SS, Rallan M, Navit P, Chandra S. Effects of carbonated drinks and fruit juices on salivary $\mathrm{pH}$ of children: an in-vitro study. Int J Sci Study 2013;1:60-69.

16. Wetton S, Hughes J, West N, Addy M. Exposure time of enamel and dentine to saliva for protection against erosion: a study in vitro. Caries research 2006;40:213-217.

17. Gray A, Ferguson MM, Wall JG. Wine tasting and dental erosion. Case report. Aust Dent J 1998;43:32-34.

18. Johansson AK, Lingström P, Birkhed D. Comparison of factors potentially related to the occurrence of dental erosion in high-and low-erosion groups. Eur J Oral Sci 2002;110:204-211.

19. Coombes JS. Sports drinks and dental erosion. Am J Dent 2005;18:101-104.

20. Sanchez GA, Fernandez De Preliasco MV. Salivary pH changes during soft drink consumption in children. Int J Paediatr Dent 2003;13:251-257.

21. Rios D, Magalhães AC, Honórico HM, Buzalaf MA, Lauris JR, Machado MA. The prevalence of deciduous tooth wear in six-year-old children and it's relationship with potential explanatory factors. Oral Health Prev Dent 2007;5:167-171.

22. Rios $\mathrm{D}$, Honório HM, Magalhães AC, Buzalaf MAR, Palma-Dibb RG, Machado MA de AM, Silva SMB. Influence of toothbrushing on enamel softening and abrasive wear of eroded bovine enamel: an in situ study. Braz Oral Res 2006;20:148-154.

23. Shellis RP, Featherstone JD, Lussi A. Understanding the chemistry of dental erosion. Monogr Oral Sci 2014;25:163-79.

24. Dawes $\mathrm{C}$. What is the critical $\mathrm{pH}$ and why does a tooth dissolve in acid? J Can Dent Assoc 2003;69:722-724.

25. Saeed S, Al-Tinawi M, Edwards M, Creanor SL, Foye RH, Gilmour WH. Evaluation of acidity and total sugar content of children's popular beverages and their effect on plaque pH. J Indian Soc Pedod Prev Dent 2010;28:189-192.
26. Panda A, Ghosh B, Pal I, Kumar V, Bhuyan L, Dash KC. Dissolution of Enamel on Exposure to Various Commercial Beverages Available in India. J Contemp Dent Pract 2017; 18:1009-1013

27. Tahmassebi JF, Duggal MS, Malik-Kotru G, Curzon ME. Soft drinks and dental health: a review of the current literature. J Dent 2006;34:2-11.

28. West NX, Hughes JA, Addy M. The effect of $\mathrm{pH}$ on the erosion of dentine and enamel by dietary acids in vitro. J Oral Rehab 2001;28:860-864.

29. Parry J, Shaw L, Arnaud MJ, Smith AJ. Investigation of mineral waters and soft drinks in relation to dental erosion. J Oral Rehab 2001;28:766-772.

30. Davis RE, Marshall TA, Qian F, Warren JJ, Wefel JS. In vitro protection against dental erosion afforded by commercially available, calcium-fortified 100 percent juices. J Am Dent Assoc 2007;138:1593-1598.

31. Chadwick BL, White DA, Morris AJ, Evans D, Pitts NB. Noncarious tooth conditions in children in the UK, 2003. Br Dent J 2006;200:379-384.

32. Attin T, Weiss K, Becker K, Buchalla W, Wiegand A. Impact of modified acidic soft drinks on enamel erosion. Oral Dis 2005; 11:7-12.

33. Lagerlof F, Dawes $C$. The volume of saliva in the mouth before and after swallowing. Journal of dental research 1984;63: 618-621.

34. Meurman JH, Frank RM. Scanning electron microscope of the effect of salivary pellicle on enamel erosion. Caries Res 1991;25:1-6.

35. Hannig M, Fiebiger M, Guntzer M, Dobert A, Zimehl R, NekrashevychY. Protective effect of the in situ formed shortterm salivary pellicle. Arch Oral Biol 2004;49:903-910. 